\title{
O debate político: um gênero para o ensino da oralidade
}

\section{Political debate: a genre for the teaching of orality}

\author{
Gustavo Limai (UFAPE) \\ Fatiha Dechicha Parahybaii (UFPE)
}

\begin{abstract}
Resumo: Situado na corrente de tradição discursiva, dada a sua recorrência na história, o debate político constitui um gênero exemplar para o ensino da oralidade. A prática linguageira e social desse gênero pressupõe saberes específicos e, em especial, a capacidade de argumentar. Este trabalho, de cunho exploratório (GIL, 2009), objetiva analisar o debate político no contexto brasileiro, sob o prisma da historicidade, de forma a verificar, por um lado, quais elementos caracterizam essa prática social. Por outro lado, examinar os elementos estáveis, bem como as possíveis mudanças ocorridas no período de tempo selecionado para a presente de pesquisa. Assim, o nosso corpus é constituído de dois exemplares de debates entre presidenciáveis realizados em contextos históricos extremos (1989 e 2018). Ancoramo-nos nos pressupostos teóricos do Interacionismo sociodiscursivo (BRONCKART, 1999, 2008) e da tradição discursiva (KABATEK, 2006) de forma a dialogar com ambas as correntes para apreender a maneira como nos relacionamos com os pré-construídos e como eles regulam o nosso agir nas atividades sociais e o nosso agir de linguagem. Com isso, buscamos focar nas dimensões ensináveis do nosso objeto de pesquisa que ancoram a construção de um modelo didático de teor exploratório.

Palavras-chave: debate político, tradição discursiva, oralidade, modelo didático.
\end{abstract}

Abstract: Considering its recurrence in history, which frames it within discursive tradition, the political debate constitutes na exemplary genre for the teaching of orality. The language and social practice of this genre implies specific knowledge and, in particular, the capacity to argue. This exploratory study (GIL, 2009) aims at analysing the political debate within the Brazilian context, through the lenses of historicity so as to verify, on the one hand, which elements characterize this social practice. On the other hand, to examine the stable elements as well as the possible changes which might have ocurred throughout the period of time selected for the present research. Hence, the corpus comprises two samples of debates 
between presidential candidates held in distant historical contexts (1989 e 2018). Sociodiscursive Interactionism (BRONCKART, 1999, 2008) and discursive tradition (KABATEK, 2006) theories are used in combination so as to comprehend how one relates to the pre-constructed elements and how they regulate one's actions within social activities together with language actions. By doing so, the work seeks to focus on the teaching dimensions of the genre political debate, which support the development of an exploratory didactic model.

Keywords: discursive tradition, political debate, orality, didactic model.

\section{Introdução}

Não se deve julgar os homens por suas opiniões, mas por aquilo que essas opiniões fazem deles.

Lichtenberg, G. Ch.

Incentivados por este dossiê temático sobre tradição discursiva e a interface com o ensino e aprendizagem de gêneros textuais, propomo-nos, neste artigo, a contribuir com esses estudos, abordando o debate político sob o prisma da historicidade, discutindo a relevância do ensino da oralidade e do gênero em foco.

Historicamente, a prática social de participação em debates (políticos) constitui uma tradição discursiva consolidada tendo em vista os registros históricos que remetem à Grécia Antiga. Naquela época, o debate público já era praticado de forma presencial para discutir assuntos de interesse da comunidade, em praça pública, a ágora (COIRO-MORAES e FARIAS, 2017). Em tempos contemporâneos, o debate faz parte do cenário político e eleitoral em inúmeros países, assumindo novas configurações e formas de apresentação e de participação. Além da transmissão radiofônica e televisiva, com o advento das tecnologias digitais da informação, abriram-se novos espaços midiáticos, consolidando e ampliando a participação dos cidadãos no processo eleitoral.

A escolha desse gênero deve-se, inicialmente, ao fato de que este é representativo da tradição discursiva (KABATEK, 2006). Ademais, partimos da premissa de que a atividade política também se faz presente no contexto das escolas públicas e particulares brasileiras a partir da constituição de grêmios estudantis e de eleição direta para representantes de turma, o que torna o ensino desse gênero ainda mais relevante.

Desse modo, iniciar o aluno nos diferentes níveis de Educação Básica à importância da prática do debate político e ao exercício da capacidade de debater questões de interesse 
de cunho político e social propicia o desenvolvimento de sujeitos críticos e cientes de seu engajamento cívico, de seus direitos e deveres, além da capacidade implícita de praticar a oralidade mediante gêneros orais, a exemplo do gênero em foco. Outrossim, trata-se de um gênero em potencial para o ensino sistemático da argumentação na escola (SCHNEUWLY e DOLZ, 2004).

Nesse sentido, lançamos aqui os seguintes questionamentos: 1) Quais são as formas de planificação do debate político? 2) Como se configura o agir de linguagem no gênero debate político? 3) Quais aspectos linguísticos, paralinguísticos, cinésicos e multissemióticos são mobilizados pelos políticos para apresentar suas propostas e planos de trabalho e argumentar com seus interlocutores bem com o público em geral? e 4) Quais são as possíveis dimensões ensináveis desse gênero no contexto escolar?

Assim, de modo a lançar luz a essas questões, em um primeiro momento, situaremos historicamente essa prática linguageira já na Grécia Antiga, mostrando igualmente a continuidade dessa tradição discursiva em séculos mais recentes. Em seguida, apresentaremos, uma breve contextualização da história do gênero debate político no Brasil, bem como os pressupostos teóricos que orientaram a realização deste estudo. $\mathrm{Na}$ sequência, procederemos a uma caracterização metodológica, momento em que evidenciaremos os critérios de constituição do corpus, e, em seguida, realizaremos o movimento de análise dos exemplares do gênero. Com base nessa análise, finalizaremos apontando para algumas dimensões que precisam ser levadas em consideração na construção de um esboço de um modelo didático do gênero debate político. Por fim, explicitaremos as nossas considerações sobre o estudo realizado.

\section{O gênero debate político em uma perspectiva histórica}

Para apreender a dimensão da tradição discursiva em torno do debate, faz-se necessário situar historicamente essa prática linguageira na participação em debates públicos, que remonta à Grécia Antiga, como mostram Coiro-Moraes e Farias (2017) e Malkopoulou (2011). Segundo a última autora, o engajamento cívico era altamente salientado por Aristóteles na medida em que permitia aos cidadãos participarem dos processos de deliberação e tomada de decisão. Malkopoulou (2011, p. 23) cita ainda o 
estadista Péricles, que defende a importância do debate ao afirmar que este não constitui um impedimento à ação. É muito mais o fato de não ser instruído pelo debate antes da chegada do momento da ação. É justamente essa visão de instrução acerca do debate que ancora nossa proposta do ensino desse gênero.

Ainda na perspectiva histórica, em séculos mais recentes, há registros, datando do século XIX, nos quais o debate político era exercido em alguns países europeus, a exemplo da Bélgica e da França, em função do sistema e pleito eleitoral ${ }^{1}$, conforme mostra Malkopoulou (2011). Essa tradição discursiva consolidou-se ao longo do século XX e continua sendo exercido pelos regimes democráticos. Essa observação corrobora o pensamento de Kabatek (2006, p. 5) ao afirmar que "Uma [...] [tradição discursiva] implica sempre a repetição de algo no tempo".

No Brasil, o primeiro debate político ocorreu no ano de 1989, período em que o país passava por um processo de redemocratização após um longo e árduo período de ditadura militar $^{2}$. O anseio coletivo de traçar novos caminhos para a história do país passava pela participação popular, por meio do voto direto para a escolha do seu representante maior, o Presidente da República, o que foi reivindicado a partir do movimento político das "Diretas Já3", que ganhou força entre os anos de 1983 e 1984. Apesar da mobilização em massa, o pleito não foi atendido e a eleição 4 para presidente no ano seguinte (1985) ainda ocorreu de forma indireta, através de um Colégio Eleitoral constituído por partidos políticos do Parlamento brasileiro.

Somente após a aprovação da Constituição de 1988, que estabeleceu, dentre outros direitos, o do voto, é que as eleições passaram a acontecer com a participação popular. Naquele contexto, 22 (vinte e dois) candidatos disputaram as eleições presidenciais em primeiro turno, dos quais 07 (sete) participaram efetivamente do primeiro debate presidencial da história do Brasil, transmitido pela Rede Bandeirantes de Televisão, no dia $17 / 07 / 1989$.

\footnotetext{
${ }^{1}$ A autora faz um estudo abrangente sobre o debate político e o voto compulsório.

${ }^{2} \mathrm{O}$ período histórico de ditadura miliar no Brasil foi de 1964 a 1985.

3 Esse movimento defendia a aprovação da Emenda Dante de Oliveira, que procurava garantir a realização de eleições presidenciais diretas em 1985. O movimento realizou campanhas em várias cidades brasileiras por meio de comícios em praças públicas, reunindo milhares de pessoas.

${ }^{4}$ A eleição foi vencida por Tancredo Neves, um dos principais representantes do movimento das "Diretas Já"
} 
Após a votação em primeiro turno, no do dia 15 de novembro de 1989 , os dois candidatos mais votados seguiram para o pleito em segundo turno, a saber: Luís Inácio Lula da Silva (Partido dos Trabalhadores - PT) e Fernando Collor de Melo (Partido da Reconstrução Nacional - PRN). Na ocasião, um segundo debate foi realizado com os presidenciáveis no dia 14 de dezembro daquele ano. Mais uma vez, a transmissão foi feita pela Rede Bandeirantes de Televisão, em parceria com o consórcio de imprensa (Rede Globo, Sistema Brasileiro de Televisão e TV Manchete).

Estabelecia-se, portanto, no cenário nacional, um gênero oral que tem como finalidade promover ao grande público o acesso às propostas e aos programas de governo dos candidatos. Com o passar dos anos, o gênero debate político foi se reconfigurando quanto às normas de funcionamento, aos suportes de transmissão, aos aspectos multissemióticos, o que inclui a acessibilidade, mas sem perder a sua forma de organização interna, como buscaremos evidenciar neste artigo.

Desse modo, em função da recorrência dessa prática comunicativa, é oportuno verificar, sob o prisma histórico, tanto os elementos estáveis e as regularidades quanto as mudanças ocorridas no gênero debate político.

\section{Interacionismo sociodiscursivo e tradição discursiva: um diálogo possível}

No escopo teórico do Interacionismo Sociodicursivo (ISD), os textos pertencem a categoria dos pré-construídos e se constituem como unidades comunicativas empíricas nas atividades de linguagem que organizam o modo de vida em sociedade (BRONCKART, 1999, 2008). Esses textos materializam-se em gêneros que, por sua vez, respondem a demandas oriundas das atividades sociais, assumindo formas e finalidades comunicativas diversas, ao mesmo tempo em que regulam as ações dos indivíduos. Daí advém a centralidade que os gêneros textuais possuem no processo de desenvolvimento humano.

$\mathrm{Na}$ tentativa de compreender, de forma mais ampla, como esses textos funcionam discursivamente, O ISD vem se apresentando como uma teoria em construção, o que se revela na busca pelo diálogo permanente com outras ciências do humano (BRONCKART, 1999), assumindo, pois, uma perspectiva transdisciplinar do conhecimento, compartilhando conceitos e concepções advindas de outras teorias cujo foco é centrado no estudo de língua 
e de linguagem. Nesse movimento, a noção de tradição discursiva (KABATEK, 2006) nos parece interessante não apenas para o resgate da historicidade dos textos, mas, sobretudo, para compreendermos como nos relacionamos e modificamos os pré-construídos e como eles regulam o nosso agir nas atividades sociais.

A noção de tradição discursiva (TD) está ancorada nas regularidades dos textos ao longo da história, em diferentes culturas e sociedades (ANDRADE e GOMES, 2018) e, embora se aproxime do conceito bakhtiniano de gêneros como formas relativamente estáveis de enunciados, diferencia-se deste por inscrever-se em um contexto mais amplo, na memória de um coletivo cujas tradições reverberam, de algum modo, nas configurações internas e nos modos de realização dos gêneros.

Partimos aqui da premissa de que o debate político se apresenta como um gênero mais ou menos estabilizado, uma vez que parece compartilhar elementos socio-retóricos e sociocomunicativos presentes em diferentes línguas. Tal aspecto se mostra relevante ao ISD no que concerne à compreensão acerca do papel dos pré-construídos nas atividades e ações de linguagem. Para os objetivos desse artigo, interessa-nos, de modo particular, incorporar os postulados da TD aos processos de didatização envolvendo a produção de textos orais e escritos, em especial à construção de um modelo didático do gênero Debate Político.

\section{O ensino da oralidade e o desenvolvimento da capacidade de argumentar}

No contexto de sala de aula, uma das dificuldades do trabalho com o oral tem sido em relação ao ensino da argumentação, que é negligenciado por muitos professores sob a crença de que a capacidade de argumentar é inata ao ser humano e, portanto, desenvolvida espontaneamente pelo indivíduo (RIBEIRO, 2009). Contrários a esse cenário, Dolz, Schneuwly e De Pietro (2004) defendem o ensino sistemático do oral e, por conseguinte, o desenvolvimento da capacidade de argumentação oral dos alunos através de gêneros formais da esfera pública, como o debate regrado, por exemplo.

Adeptos a essa perspectiva e considerando a importância de argumentar dentro e fora do contexto escolar, sustentamos aqui uma organização curricular com base em gêneros que possibilite o desenvolvimento gradual da argumentação em diferentes etapas 
do processo de escolarização e não apenas no Ensino Médio, como geralmente tem ocorrido (KERSH, 2014; LIMA, 2016).

Quanto aos "porquês" de se ensinar a argumentar na escola, Ribeiro (2009) afirma que essa capacidade é importante na formação de um cidadão capaz de saber lidar com ideias e valores contrários aos seus, de questionar e se posicionar a partir do que foi dito pelo outro. Ademais, os gêneros da ordem do argumentar também favorecem o desenvolvimento de capacidades linguístico-discursivas dos alunos. A esse respeito, Leitão (2014, p.65) ainda esclarece que o trabalho com a argumentação é necessário e oportuno pelas seguintes razões:

A primeira é de natureza desenvolvimentista: se a criança é capaz de se engajar em argumentação já desde muito cedo, é possivel criar situações em que ela possa fazê-lo em sala de aula e a serviço de objetivos educacionais específicos. A segunda é que a argumentação desencadeia processos essenciais à aprendizagem e ao desenvolvimento do pensamento reflexivo - objetivos centrais da ação pedagógica em todas as etapas da escolarização formal. A terceira e última razão remete aos temas em torno dos quais a argumentação pode ser gerada em sala de aula.

No que concerne especificamente aos gêneros orais, observa-se a presença de movimentos discursivos característicos da argumentação (justificativa/sustentação, refutação e negociação), atuação de operadores argumentativos e situação argumentativa definida pela presença do interlocutor com quem se argumenta). Esses gêneros vão desde os mais espontâneos, como diálogo argumentativo, que é destacado como a primeira forma de manifestação da linguagem argumentativa no meio social (RIBEIRO, 2009), até os mais complexos, como o debate, que, apesar de assumir diferentes versões (DOLZ, SCHNEUWLY e DE PIETRO, 2004), é caracterizado por uma linguagem que busca explicitar determinados posicionamentos mediante argumentos e contra-argumentos, dados e informações suplementares cujo objetivo é convencer o outro.

Desse modo, na sala de aula, faz -se necessário instruir o aluno de forma a explorar a sua capacidade de argumentação, sobretudo, em virtude do fato de que as capacidades de linguagem de argumentação se desenvolvem mais tarde, conforme esclarecem Golder (1996) e Dolz e Schneuwly (1996). O aluno aprende que, ao argumentar, ele defende seu posicionamento. Trata-se de um agir de linguagem que o leva a expressar sua opinião 
almejando, ao mesmo tempo, transformar a opinião do seu interlocutor na medida em que argumentar implica o "eu e o outro" (SCHNEUWLY, 1988, p. 161, grifo nosso).

Em situação de debate político na sala de aula, por exemplo, o aluno precisa não só apresentar um programa de ações a realizar, mas, sobretudo, saber mobilizar, organizar e refutar argumentos quando é perguntado ou interpelado sobre determinado ponto ou assunto. Nessa dinâmica, o proponente ao posto de representante da turma ou do grêmio estudantil precisa saber argumentar oralmente de modo a buscar a adesão dos colegas ao seu projeto.

Assim, na esteira do que propõem alguns estudos recentes com um viés mais propositivo para o ensino da oralidade (MAGALHÃES, BUENO e COSTA-MACIEL, 2021), pretendemos com esta contribuição avançar nas reflexões sobre as possibilidades de planificação do ensino de gêneros orais, em especial os que favorecem o desenvolvimento da argumentação, propondo alguns aspectos a serem considerados na construção do modelo didático do gênero debate político.

\section{Metodologia}

O presente artigo é fruto de um estudo exploratório (GIL, 2009) desenvolvido no âmbito do grupo HISTEL (Historicidade dos Textos e Ensino de Língua)5. Os procedimentos metodológicos incluíram 02 etapas, a saber: 1) coleta, transcrição ${ }^{6}$ e análise de 02 (dois) exemplares autênticos do gênero debate político no contexto brasileiro; 2) delimitação das dimensões ensináveis do gênero debate político com vistas à proposição de aspectos a serem considerados na construção de um esboço de um modelo didático desse gênero.

Assim, realizamos, em um primeiro momento, um recorte temporal selecionando dois debates envolvendo presidenciáveis em períodos distintos da história do Brasil. $\mathrm{O}$ primeiro, como já mencionamos, foi realizado no dia 14 de dezembro 1989 e pode ser considerado um marco histórico por ser o primeiro debate político para eleições em

\footnotetext{
5 O Grupo de Pesquisa sobre a Historicidade do Texto e Ensino de Língua (HISTEL) envolve estudiosos da Université de Genève (Suiça), Universidade Federal do Ceará (Brasil), Universidade Federal de Pernambuco (Brasil), Universidade Federal Rural de Pernambuco (Brasil), Universidade Federal do Agreste de Pernambuco (Brasil), Universidade Nacional de Rosario (Argentina) e Universidade Nova de Lisboa (Portugal).

${ }^{6}$ As transcrições foram realizadas conforme as normas estabelecidas internamente pelo grupo de pesquisa HISTEL.
} 
segundo turno transmitido pela televisão brasileira. Já o segundo é representativo das últimas eleições presidenciais de 2018 em primeiro turno e foi transmitido pelas redes de televisão e pela internet, no dia 26 de setembro de 2018 .

A coleta dos exemplares ocorreu mediante busca na plataforma do YouTube, no mês de junho de 2021. Logo, o nosso corpus foi composto por um exemplar de debate presidencial em segundo turno e outro em primeiro turno, com um recorte histórico de 29 anos entre eles, totalizando 4 horas e 45 minutos de material analisado. A opção por não analisar um debate também em segundo turno no ano de 2018 deve-se ao fato de que, naquele pleito, não houve debate entre os dois candidatos mais votados em $1^{\circ}$ turno, visto que um dos presidenciáveis ${ }^{7}$ se recusou a participar de todos os debates para os quais foi convidado.

Em seguida, apoiados nos estudos do ISD sobre oralidade e no paradigma da Tradição Discursiva, realizamos uma análise comparativa dos dois debates observando as regularidades do gênero quanto à sua forma de organização, posição dos participantes, disposição dos lugares, meios cinésicos e paralinguísticos, estruturas linguísticas e utilização de recursos multissemióticos. Por fim, elencamos alguns aspectos a serem considerados na construção de um modelo didático do gênero debate político.

\section{Análise dos debates políticos}

O recorte histórico dos exemplares de debates políticos nos forneceu indícios das possíveis regularidades do gênero, em especial no que concerne ao aspecto composicional e à linguagem. Verificamos, por exemplo, que as formas de planificação do gênero se mantêm, a saber: abertura, apresentação das regras do debate, realização do debate e fechamento. Abaixo, um quadro síntese dessas partes nos dois exemplares de debate analisados:

Quadro 1: formas de planificação do Debate Político

\begin{tabular}{|l|l|}
\hline Debate Presidencial-1989 & Debate Presidencial-2018 \\
\hline 1. Abertura & 1. Abertura \\
\hline
\end{tabular}

\footnotetext{
${ }^{7}$ Fazemos referência aqui ao então presidenciável Jair Messias Bolsonaro (Partido Social Liberal - PSL).
} 
O mediador:

1.situa o contexto de realização do debate (transmissão pela TV);

2. informa ao público sobre a organização do debate: os blocos (4 blocos, três temáticos e um atemático), a duração do debate ( 2 horas e 30 minutos);

3. apresenta os candidatos participantes e suas respectivas filiações partidárias;

4. apresenta os especialistas (jornalistas) que mediarão o debate e os que farão questionamentos aos candidatos em cada bloco.

2. Apresentação das regras do debate O mediador apresenta as regras do debate:

1. O mediador faz uma pergunta no início de cada bloco. Candidatos A e B respondem a mesma pergunta, conforme sorteio prévio;

2. especialista convidado (jornalista) pergunta (30 segundos). Candidato A responde $(2$ minutos). Candidato $B$ comenta (1 minuto). Candidato A faz a réplica (1 minuto)

3. no último bloco, candidatos fazem perguntas entre si, com direito a comentários e réplicas.

Não há plateia
O mediador:

1. situa o contexto de realização do debate (transmissão pela TV e pela internet, com possibilidade de interação com os espectadores via chat e redes sociais, mediante utilização de hashtags);

2. apresenta os candidatos participantes e suas respectivas filiações partidárias;

3. mediador justifica a ausência de um presidenciável e informa ao público a organização do debate (3 blocos com temas livres).

2. Apresentação das regras do debate O mediador apresenta as regras do debate no início de cada bloco

Regras do $1^{\circ}$ bloco:

1. Candidato pergunta a candidato em ordem pré-definida por sorteio. A pergunta deverá ser feita em até 30 segundos.

2. Cada candidato faz uma pergunta e cada participante só pode ser escolhido uma vez para responder. A resposta deverá ser dada em 1 minuto e 15 segundos.

3. O candidato que fez a pergunta tem direito à replica (30 segundos) e o candidato que respondeu tem direito à tréplica (45 segundos);

Há uma plateia

Mediador solicita a plateia que não se manifeste durante o debate.

O mediador informa que, em caso de ofensa, o candidato que se sentir ofendido poderá solicitar direito de resposta, o qual será analisado pela comissão jurídica do debate. Se concedido, terá duração de 1 minuto. 


\begin{tabular}{|c|c|}
\hline & $\begin{array}{l}\text { Regras do } 2^{\circ} \text { bloco: } \\
\text { 1. Jornalista faz uma pergunta ao candidato } \\
\text { da sua escolha (30 segundos). Cada } \\
\text { candidato só poderá responder uma vez (1 } \\
\text { minuto). } \\
\text { 2. Jornalista complementa a pergunta (15 } \\
\text { segundos); } \\
\text { 3. Candidato faz a réplica ( } 45 \text { segundos). } \\
\text { Regras do } 3^{\circ} \text { bloco: } \\
\text { 1. Candidato pergunta a candidato em } \\
\text { ordem pré-definida por sorteio. A pergunta } \\
\text { deverá ser feita em até } 30 \text { segundos; } \\
\text { 2. Cada candidato faz uma pergunta e cada } \\
\text { participante só pode ser escolhido uma vez } \\
\text { para responder. A resposta deverá ser dada } \\
\text { em } 1 \text { minuto e } 15 \text { segundos; } \\
\text { 3. O candidato que fez a pergunta tem } \\
\text { direito à replica ( } 30 \text { segundos) e o candidato } \\
\text { que respondeu tem direito à tréplica ( } 45 \\
\text { segundos); } \\
\text { 4. Cada candidato faz suas considerações } \\
\text { finais ( } 1 \text { minuto para cada) }\end{array}$ \\
\hline 3. Realização do debate & 3.Realização do debate \\
\hline $\begin{array}{l}2^{\circ} \text { bloco temático (Economia) } \\
3^{\circ} \text { bloco temático (Questão social) } \\
4^{\circ} \text { bloco temático (Justiça e democracia) } \\
5^{\circ} \text { bloco atemático (tema livre) }\end{array}$ & Todos os blocos são "Tema Livre" \\
\hline $\begin{array}{l}\quad \text { 4. Fechamento } \\
\text { - Candidatos proferem as palavras finais, } \\
\text { conforme ordem de sorteio prévio ( } 3 \\
\text { minutos para cada); } \\
\text { - Mediador realiza os agradecimentos e } \\
\text { encerra o debate. }\end{array}$ & $\begin{array}{l}\text { 4. Fechamento } \\
\text { - Candidatos proferem as palavras finais } \\
\text { conforme ordem de sorteio prévio ( } 1 \text { minuto } \\
\text { para cada) } \\
\text { - Mediador realiza os agradecimentos e } \\
\text { encerra o debate. }\end{array}$ \\
\hline
\end{tabular}

Fonte: elaborado pelos autores

O primeiro exemplar de debate está particionado em quatro vídeos que, juntos, totalizam 02 horas e 54 minutos de gravação. O material coletado apresenta-se como um 
registro histórico do primeiro debate em segundo turno entre presidenciáveis no Brasil. Como já explicitamos, naquela ocasião, a disputa para o Planalto ${ }^{8}$ se deu entre os candidatos Luís Inácio Lula da Silva (PT) e Fernando Collor de Melo (PRN), conforme ilustrações abaixo:

Figura 1: Debate Presidencial - $2^{\circ}$ turno (1989)

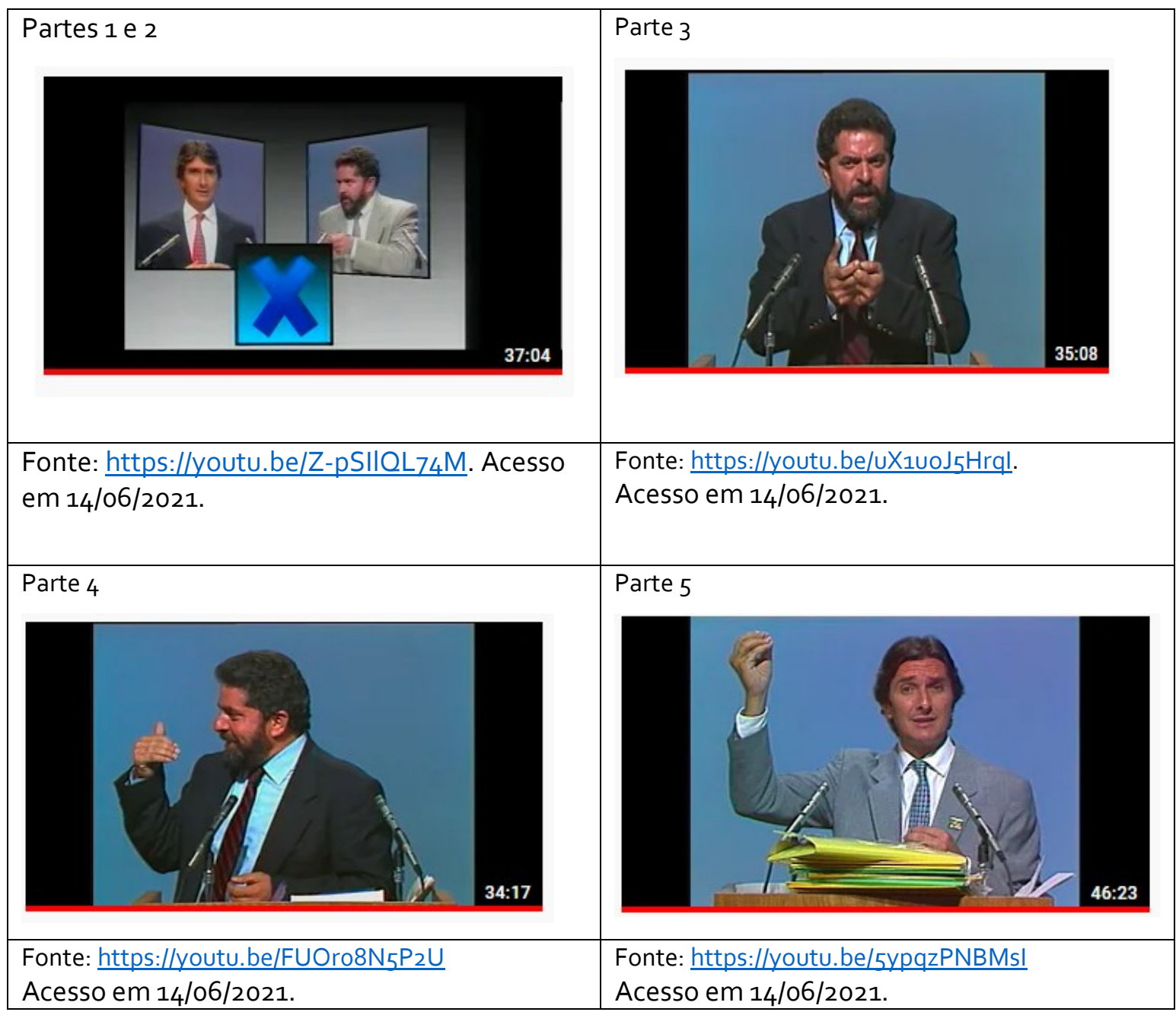

Fonte: elaborado pelos autores

O debate acima foi transmitido para todo o território nacional pela Rede Bandeirantes de Televisão, em parceria com outras emissoras (Rede Globo, Sistema Brasileiro de Televisão e Rede Manchete), no dia 14/12/1989. No estúdio, além dos mediadores, estavam presentes os dois candidatos e outros jornalistas convidados, os quais

\footnotetext{
${ }^{8}$ Fazemos referência aqui ao Palácio do Planalto, situado na Praça dos Três Poderes, em Brasília. Local de trabalho da Presidência da República do Brasil.
} 
realizaram perguntas aos presidenciáveis. A disposição dos participantes era a seguinte: mediador (um jornalista) em pé, ao centro; candidatos também em pé, nas laterais (à direita e à esquerda do mediador). Todos estavam usando trajes sociais (terno e gravata) e posicionados por trás de uma tribuna sobre a qual havia dois microfones e materiais impressos para consulta. À frente, ficava a bancada com jornalistas convidados. Não havia plateia.

O debate foi dividido em 4 blocos (3 temáticos ${ }^{9}$ e 1 atemático), cada qual realizado sob a mediação de um jornalista representante de uma das emissoras que integrava o consórcio de imprensa. Conforme as regras preestabelecidas, no início dos três primeiros blocos, um jornalista convidado deveria fazer uma pergunta, a qual deveria ser respondida por um dos candidatos, obedecendo à ordem de um sorteio prévio. O outro candidato teria direito a comentar a resposta do seu adversário. Por fim, o candidato que respondeu teria direito à replica. Ficou também estabelecido que o jornalista que elaborou a pergunta não poderia questionar as respostas dos candidatos. No último bloco, os candidatos deveriam fazer perguntas entre si, com direito a comentários e réplicas.

Em relação à linguagem, observamos, por exemplo, a utilização de estruturas descritivas e/ou expressões que denotam: 1) uma polarização de grupos políticos ("[...] ele faz parte daquele grupo de políticos que age como se fosse aquele início do programa da Xuxa. Antes da eleição, 'beijinho, beijinho", depois das eleições, é 'tchau, tchau'. É cinco anos colocando a polícia para reprimir o povo [...]; "aqueles que são da classe dominante estão com o meu adversário"; "essa elite política está do lado de lá"); 2) uma identificação com determinado segmento do eleitorado ("pessoas humildes, tementes a Deus"); 3) uma projeção de autoimagem junto ao eleitorado ("Eu que já fui prefeito, que já fui governador do Estado, portanto, tenho experiência administrativa, coisa que o meu adversário não tem [...]"); 4) uma situação econômica ou social do país ("a inflação que aí está, ela é causada, em primeiro lugar, pelo desequilibrio das contas, ou seja, o governo gasta mais do que arrecada"; "nós temos milhões de brasileiros que passam quatro dias sem comer uma única refeição"); ou, ainda, 5) uma ofensa ao deboche ao adversário por meio de metáforas e alegorias ("ele é uma marionete"; "mamando nas tetas do governo").

\footnotetext{
${ }^{9}$ Os temas foram: Economia (bloco 1), Questão social (bloco 2), Justiça e democracia (bloco 3).
} 
Ressaltamos ainda o uso de construções perifrásticas para realizar promessas ao eleitorado ("nós vamos enfrentar os problemas e vamos resolvê-los [...] Vamos, sim, aumentar o salário-mínimo, vamos levar a comida para a mesa do pobre, vamos dar casa, vamos dar transporte barato, vamos dar saúde e educação [...],") tornando a linguagem mais assertiva. Outro aspecto a ser destacado é o tom de voz dos presidenciáveis, que, por vezes, foi bastante elevado, bem como expressões faciais e gestos bem acentuados, como evidenciam as imagens abaixo:

Figura 2: Gestos dos Presidenciáveis - Debate (1989)
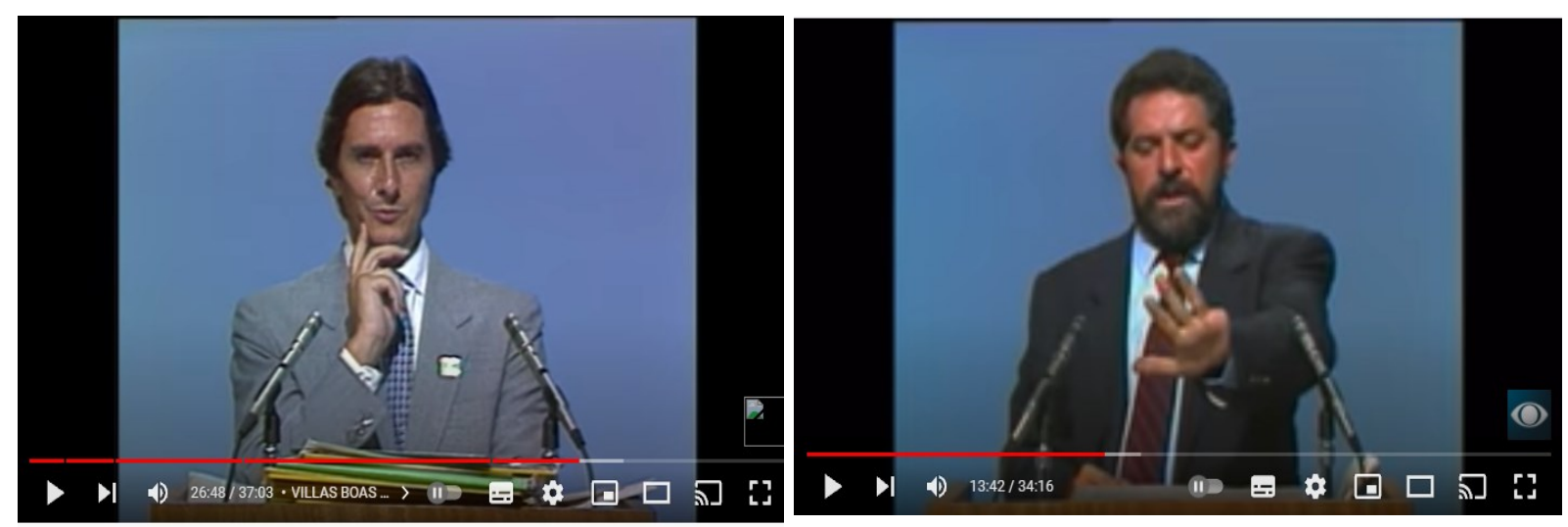

Fonte: https://youtu.be/FUOro8 ${ }_{5} \mathrm{P}_{2} \mathrm{U}$. Acesso em 14/06/2021.

As imagens acima são representativas de episódios em que os candidatos se utilizam dos gestos para construir significação. À esquerda, o candidato Fernando Collor (PRN) posiciona a mão abaixo do queixo para reforçar um tom de desconfiança em relação ao que o seu opositor acabara de declarar. À direita, a imagem do momento em que o candidato Luís Inácio Lula da Silva (PT) projeta sua mão esquerda para frente, mostrando o dedo amputado $^{10}$, no exato momento em que fazia uma crítica ao sistema de saúde público brasileiro.

Já o segundo exemplar analisado é referente a um debate presidencial em primeiro turno, ocorrido no dia no dia 26/09/2018, e envolveu 08 (oito) presidenciáveis. O evento foi organizado pelo consórcio de imprensa formado pelo Portal UOL, Folha de São Paulo e o Sistema Brasileiro de Televisão (SBT) e teve transmissão simultânea pela TV aberta (SBT) e pela internet (Portal UOL), com duração de 1 hora e 51 minutos.

\footnotetext{
${ }^{10} \mathrm{O}$ candidato teve o dedo amputado em decorrência de um acidente de trabalho.
} 
Figura 3: Debate Presidencial $-1^{\circ}$ turno (2018)

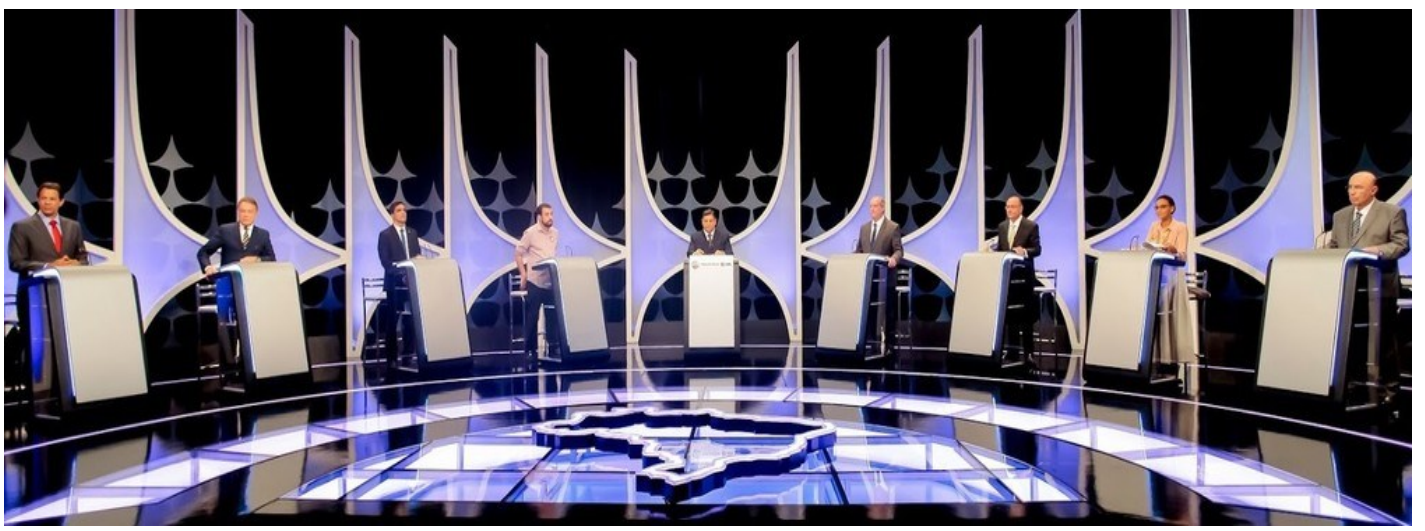

Foto: https://g1.globo.com/politica/eleicoes/2018/noticia/2018/og/26/quinto-debate-na-tv-reune-8candidatos-a-presidente-saiba-o-que-eles-disseram.ghtml

Fonte: https://youtu.be/MSgq-tZiAkU. Acesso em 14/06/2021

Tal como no debate de 1989, a disposição dos participantes não mudou. O mediador (um jornalista) permanece ao centro e, nas laterais, os presidenciáveis, 04 (quatro) de cada lado, formando um semicírculo. Também não observamos mudanças significativas nos trajes dos candidatos, exceto pelo candidato à esquerda do mediador, que não usava terno e gravata como os demais presidenciáveis do sexo masculino. Todos estavam posicionados de pé, por trás de uma tribuna sobre o qual havia dois microfones. Além do mediador, alguns dos candidatos trouxeram materiais impressos para consulta, os quais ficaram dispostos sobre a sua bancada. À frente, estavam os jornalistas convidados e a plateia, a qual foi orientada a não se manifestar durante o debate.

O debate foi organizado em três blocos, com temas livres. Nos blocos 1 e 3, os presidenciáveis realizaram perguntas entre si, com direito a réplica e tréplica e com tempo estabelecido para a fala. Já o bloco 2 foi destinado às perguntas dos jornalistas aos candidatos. Ao final, cada presidenciável realizou, em um tempo reduzido, as suas considerações e, em seguida, o debate foi encerrado pelo mediador.

Quanto à linguagem, embora houvesse uma orientação quanto a possíveis ofensas entre os candidatos, observamos, em alguns momentos, que o discurso dos presidenciáveis assumia um tom mais acusatório ("você não é nenhum santo [...]"; "eu e meu partido não temos rabo preso [...]"; "não fui desocupado [...]", "o senhor fica roubando a nação [...]"). Também ficou evidente o uso de estruturas descritivas como forma: 1) de enfatizar os feitos realizados ("primeiro, São Paulo cresceu no IDEB, cresceu no IDEB no segundo ciclo, perdeu zero vírgula um no Ensino Médio $\left.[\ldots]^{\prime \prime}\right) ; 2$ ) de destacar ações não realizadas pelos seus 
adversários ("eu sou professor e dei aula durante o seu governo. Faltava giz na sala de aula, faltava papel higiênico no banheiro das escolas, professores desvalorizados, até escola você quis fechar, mas os estudantes secundaristas não deixaram"); ou ainda 3) sinalizar para algum cenário social ou econômico do país ("O Brasil vive uma situação de injustiça social. Aqueles que se aposentam mais cedo são aqueles que ganham mais e isso é escondido da população. Aqueles que ganham menos, eles têm que chegar aos sessenta e cinco anos de idade para se aposentar [...]). Também foi perceptível o uso de construções perifrásticas para assumir ou reiterar o compromisso na realização de algumas ações dos programas de governo ("nós temos que ter uma pauta em que as mulheres sejam protagonistas [...]"; "é necessário também que o Brasil fortaleça uma indústria de saúde [...]")

No que concerne aos aspectos paralinguísticos, e cinésicos, registramos algums momentos em que os candidatos sinalizavam para os telespectadores e internautas com algum gesto representativo, como podemos observar nas ilustrações abaixo:

Figura 4: gestos dos candidatos - Debate (2018)
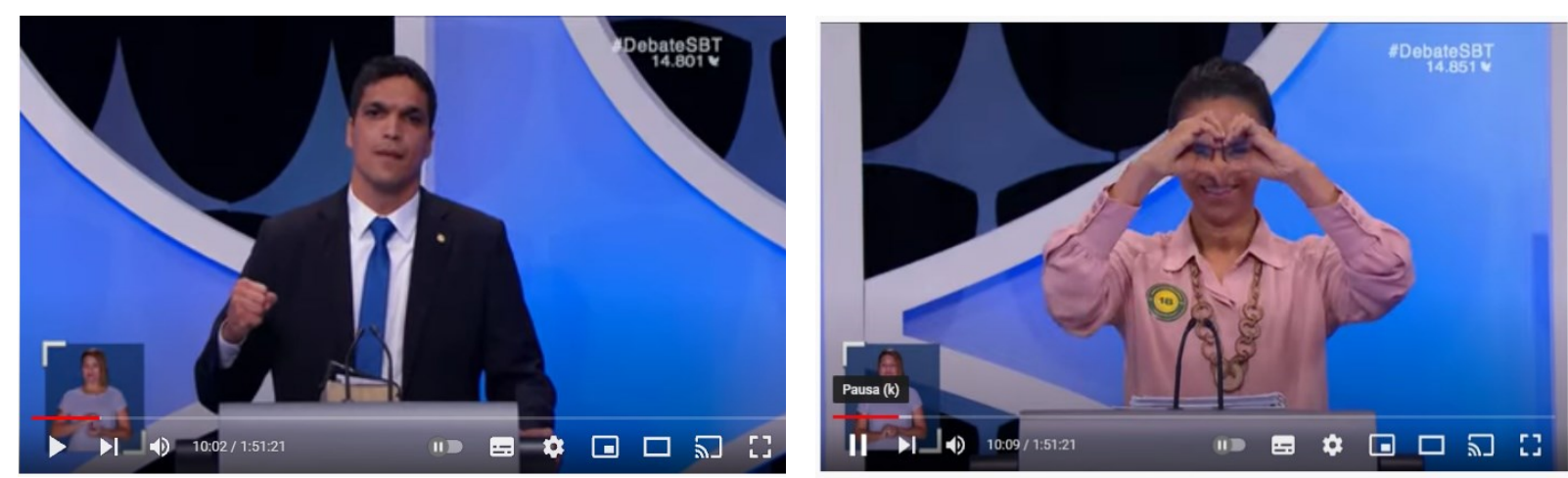

Fonte: https://youtu.be/MSgq-tZiAkU . Acesso em 14/06/2021

Acima, observamos cenas em que dois dos oito candidatos realizaram gestos quando foram anunciados ao público. À esquerda, o candidato Cabo Daciolo (Patriota) levanta o punho cerrado, o que aponta para um gesto de firmeza, força e confiança. $\grave{A}$ direita, a candidata Marina Silva (REDE) realiza um gesto com as duas mãos formando um coração, talvez numa tentativa de mostrar empatia com os eleitores.

\section{Aspectos a serem considerados na construção do modelo didático do gênero debate político}


Considerando as regularidades do gênero debate político observadas em tempos históricos distintos, sugerimos a observância de alguns aspectos da oralidade que se constituem como dimensões ensináveis em potencial. Tais aspectos irão orientar, em um estudo posterior, a elaboração de um modelo didático deste gênero para o ensino da oralidade na escola. São eles:

1. Respeito às normas do debate;

2. Gerenciamento do tempo;

3. Respeito ao turno de fala do outro;

4. Atenção aos aspectos paralinguísticos, cinésicos e multissemióticos implicados na construção da significação;

5. Uso de estruturas descritivas

6. Uso do tempo verbal adequado: presente e futuro e construções perifrásticas promessas de ações de governo;

7. Respostas claras aos questionamentos;

8. Argumentação e contra argumentação e força argumentativa

9. Linguagem formal e oralidade

10. Metáforas e alegorias

11. Linguagem não ofensiva

\section{Considerações finais}

À guisa de conclusão, convém salientar que o recorte analítico contemplado no presente estudo abrange momentos históricos relativamente distantes, porém representativos de cenários políticos importantes no Brasil. O recorte de apenas dois exemplares do gênero deve-se, em primeiro lugar, ao fato de não encontrarmos registros de debates entre presidenciáveis anterior ao final dos anos 80. Segundo, pelo fato de esses exemplares serem representativos de períodos históricos extremos.

Contudo, considerando os limites de um estudo que analisa unicamente dois exemplares do gênero debate político, foi possível detectar regularidades e mudanças, de 
modo que a análise permitiu delinear alguns aspectos constitutivos dessa prática linguageira que guiarão, em um estudo posterior, a elaboração do modelo didático.

A análise das regularidades do gênero debate político revelou que as formas de planificação permaneceram praticamente inalteradas (abertura, apresentação das regras, realização do debate e fechamento).

Por outro lado, também percebemos nuances de mudanças em relação à linguagem e à postura dos participantes ao longo da história que precisam ser contempladas no planejamento e serem alvo de reflexão e discussão na sala de aula. Também ficou clara a necessidade de levarmos em conta, na construção de um modelo didático desse gênero, os aspectos paralinguísticos, multissemióticos e cinésicos envolvidos na construção da significação, atentando para as adequações quanto aos objetivos didáticos de acordo com etapa de escolarização e a faixa etária dos alunos.

Pretendemos, assim, em estudos futuros, além de desenvolver o modelo didático do gênero debate político, ampliar as nossas reflexões sobre esse gênero à luz do diálogo entre o ISD e a Tradição Discursiva, de modo, por exemplo, a observar possíveis influências de outras línguas e culturas na configuração e no modo de realização desse gênero.

\section{Referências}

ANDRADE, Maria Lúcia C.V.O.; GOMES, Valéria Severina. Tradições discursivas: reflexões conceituais. In: ANDRADE, Maria Lúcia C.V.O.; GOMES, Valéria Severina (coord.). Tradições discursivas do português brasileiro: constituição e mudança dos gêneros discursivos. São Paulo: Contexto, Vol III, 2018. p. 23-44.

BRONCKART, Jean-Paul. O agir nos discursos: das concepções teóricas às concepções dos trabalhadores. Campinas, SP: Mercado de Letras, 2008.

BRONCKART, Jean-Paul. Atividades de linguagem, textos e discursos: por um interacionismo sócio-discursivo. São Paulo: EDUC, 1999.

COIRO-MORAES, Ana Luiza.; FARIAS, Victor Varcelly Medeiros. O exercício da cidadania da ágora grega ao site de rede social digital. In: Revista Extraprensa 11(1): 2017, p. 74-91.

DOLZ, Joaquim.; SCHNEUWLY, Bernard. Apprendre à écrire ou comment étudier la construction de capacités langagières: études de linguistique appliquée-ELA 101. Paris: Didier Érudition, 1996. p 73-86. 
DOLZ, Joaquim; SCHNEUWLY, Bernard; DE PIETRO, Jean François. Relato da Elaboração de uma Sequência: O Debate Público. In: SCHNEUWLY, Bernard. DOLZ, Joaquim. Gêneros Orais e Escritos na Escola. Campinas, SP: Mercado de Letras, 2004. p. 243-279.

GIL, Antonio Carlos. Como elaborar projetos de pesquisa? São Paulo: Atlas, 2009. 4 ed.

GOLDER, Caroline. Le développement des discours argumentatifs. Lausanne: Delachaux et Niestlé, 1996.

KABATEK, Johannes. Tradições discursivas e mudança linguística. In: LOBO, Tânia; RIBEIRO, Ilza; CARNEIRO, Zenaide; ALMEIDA; Norma (eds) Para a história do português brasileiro: novos dados, novas análises, Salvador: EDUFBA, 2006.

KERSCH, Dorotea Frank. Sobre as dificuldades e desafios de se trabalhar com gêneros do domínio do argumentar. In: GUIMARÃES, Ana Maria de Mattos; KRESCH, Dorotea Frank. (orgs.) Caminhos da construção: projetos didáticos de gênero no domínio do argumentar. Campinas, SP: Mercado de Letras, 2014.

LEITÃO, Selma. Argumentação na sala de aula: argumentar para aprender e aprender para argumentar. In: LEAL, Telma Ferraz e SUASSUNA, Lívia. Ensino de Língua Portuguesa na Educação Básica: Reflexões sobre o currículo. Belo Horizonte: Autêntica Editora, 2014. p. 95-115.

LIMA, Gustavo Henrique da Silva. O que eu ensino quando ensino gêneros? Um estudo sobre as ressignificações do agir didático do professor de língua portuguesa. Tese de Doutorado (Letras). Recife: PPGL/ UFPE, 2016.

MAGALHÃES, Tânia; BUENO, Luzia; COSTA-MACIEL, Débora. Oralidade e gêneros orais: experiências na formação docente. São Paulo: Pontes Editores, 2021.

MALKOPOULOU, Anthoula. Democracy's duty: the history of political debates on compulsory voting. PhD Dissertation, University of Jyväskylä, 2011. Disponivel em: $<$ https://www.academia.edu/5396760/Anthoula_Malkopoulou_DEMOCRACYS_DUTY_THE_HISTO RY_OF_POLITICAL_DEBATES_ON_COMPULSORY_VOTING > Acesso em 8 de outubro de 2021.

RIBEIRO, Roziane Marinho. A Construção da Argumentação no Contexto de Ensino. São Paulo: Cortez, 2009.

SCHNEUWLY, Bernard; DOLZ, Joaquim. Gêneros orais e escritos na escola. Tradução Roxane Rojo e Glaís Cordeiro. Campinas, SP: Mercado de Letras, 2004.

SCHNEUWLY, Bernard. Le langage écrit chez l'enfant: la production des textes informatifs et argumentatifs. Paris: Delachaux et Niestlé, 1988.

\footnotetext{
i Professor Adjunto III na Universidade Federal do Agreste de Pernambuco e do Programa de Pós-Graduação em Educação Contemporânea (UFPE). Vice-líder do grupo Texto, Escrita e Sala de Aula (TEcSA/CNPq) e
} 
pesquisador do Núcleo de Pesquisa em Discurso e Ensino (NUPEDE/CNPq) e do grupo Historicidade dos Textos e Ensino de Língua (HISTEL).

E-mail: ghlima.prof@gmail.com

ii Professora da Universidade Federal de Pernambuco-Departamento de Letras (Licenciatura em Língua Inglesa). Professora no Mestrado Profissional em Letras-Profletras da UFPE. Doutorado em Linguística pela UFPB e Pós-doutorado na UFC. É membro do Grupo de Estudos e Pesquisas em Linguística Aplicada (GEPLA) e do Grupo Historicidade dos Textos e Ensino de Língua (HISTEL).

E-mail: fatihadpb@gmail.com 